\title{
How Does Product Advertising Information Affect Consumers' Online Shopping Intention in the Context of Cognitive Lock-in
}

\author{
Xinyang Wu, Baocheng Sun \\ School of Marketing \& Logistics, Nanjing Financial \& Economic University, Nanjing 210023, China
}

\begin{abstract}
Under the situation of online shopping, the effectiveness of online advertising has become the focus of theoretical and practical circles. Using the experimental research method, this paper explores the influence mechanism of the interaction between consumers' cognitive lock-in regulation focus and online advertising information framework on consumers' purchase intention, and the mediating role of consumers' purchase decision-making model. The results show that consumers' cognitive lock-in moderation focus has a moderating fitting effect in the interaction between online advertising information framework and consumers' purchase decision-making model and purchase intention. Consumers' purchase decision-making model is the intermediary variable of consumers' cognitive lock-in moderation focus and online advertising information framework influencing consumers' purchase intention. Therefore, the e-commerce platform should have a more in-depth insight into consumers, set up more rich online shopping experience scenarios, improve the pertinence of advertising content, and achieve accurate push.
\end{abstract}

Keywords: Consumer cognitive lock-in, Regulatory focus, Regulatory fit, Online advertising information framework.

\section{Introduction}

The influence of advertising on consumer buying behavior is undeniable, otherwise there would not be so many businesses investing huge sums of money in advertising like a flying moth darts into the fire [1] .In the online shopping environment, consumers are confronted with more complex information about products and advertisements, while online businesses are faced with a new generation of consumers who have more sources of information and more variable in psychology and cognition, so how to deliver more attractive and targeted online advertising messages to consumers has become the focus of theoretical and practical field.

Advertising is a message in nature, and from the perspective of message framing, the statement mode of advertisement is divided into positive statement emphasizing the benefits that can be gained by shopping or consuming and negative statement emphasizing the benefits that cannot be gained or the losses that can be suffered by not buying or consuming. As the recipient of the information, the consumer's experience with the non-transferable skills of a particular interface and product will cause them to 'lock in' to a familiar website or shopping scenario, even if there is a better option, and this 'cognitive lock-in', which takes personal preferences and various switching costs into account, will keep consumers loyal to or dependent on a product or a shopping site [2]. It has been shown that the expected benefits (including point rewards, membership discounts, subsequent purchase concessions, emotional benefits of existing service processes, etc.) and/or cognitive costs (including cognitive search costs, cognitive transaction costs and cognitive switching costs, etc.) are the underlying causes of consumer cognitive lock-ins [3] [4], and therefore, consumer cognitive lock-ins has what Higgins calls a regulatory orientation (facilitative/defensive) attribute [5] [6]. In summary, this paper will use an experimental research method to purposefully manipulate certain factors or conditions that influence consumers' online purchasing behavior to investigate whether online advertising message framing matches the moderating orientation of consumers' cognitive lock-in and has a moderating matching effect with consumers' purchase decision patterns (intuition-based/ rational-based) [7] and their purchase intentions.

\section{Review of Relevant Literature and Research Hypotheses}

\subsection{Consumer Cognitive Lock-in and its Regulatory Orientation}

Consumer shopping behaviour is a process in which consumers use their perception, attention, memory, thinking and other cognitive abilities to make choices and judgments about shopping situations. Studies have shown that, driven by the maximization of future benefits and/or the minimization of immediate (switching) costs, consumers tend to choose more favorable or accessible trading methods [8]. Therefore, in the consumer field, when consumers pay a certain initial cost during the consumption process (including information search cost, product knowledge learning effort, time and energy consumption, etc.), the possibility of re-searching for information or switching consumption behavior will show a tendency to decrease or disappear, that is, there is a consumer lock-in phenomenon. That is to say, when consumers repeat consumption or use a specific product, brand or shopping scene, they often form cognitive lock-in, which is a very important factor that affects consumers' purchasing behavior, even if this immediate benefit will erode future earnings, especially in the network environment, this phenomenon of consumer cognitive lock-in is particularly obvious. Oliver's research found that when consumers evaluate cognitive cues based more on "attribute performance" rather than "content performance," they are locked into a specific website. Because of the high cognitive cost, consumers often visit favorite websites instead of trying new ones. Searching on favorite or familiar websites is more efficient than knowing a new website [9]. Therefore, consumers are likely to be locked 
into a $\mathrm{B} 2 \mathrm{C}$ website or shopping scene that can obtain useful information at low cognitive search costs.

The root cause of cognitive lock-in in the online shopping context is that either the consumer's perceived switching costs are higher than their perceived switching benefits, or the consumer's perceived existing benefits are higher than their perceived switching benefits, so the source of cognitive lock-in is those factors that can cause low switching benefits and high switching costs, or high existing benefits and low existing costs. Fang Shirong and others believe that customer transfer barriers, namely customer lock-in, can be divided into two types: positive and negative. Positive transfer barriers refer to the perceived advantages of alternative shopping sites and the disadvantages and risks of existing suppliers, while negative transfer barriers refer to the benefits customers gain from existing shopping sites or the risks and costs of switching suppliers [10]. Sylvain and others found that the switch in consumer behaviour after repeated consumption or use of a particular product, brand or online shopping environment implies a higher 'cognitive load'. Thus, the above-mentioned adjustment orientation of consumer 'cognitive lock-in' to maximize benefits (facilitative orientation) or minimize losses (defensive orientation) can also be a reasonable explanation of the role of matching between consumer 'cognitive lock-in' and relevant information frameworks (framing) on their decision outcomes [11].

\subsection{Message Framing in Online Advertising - Positive and Negative Statements}

The theory of message framing is derived from the expectancy theory proposed by Kahneman and Tversky, which states that consumers focus on avoiding risk when considering gains (defensive orientation) and tend to be more risk-averse when considering losses (facilitative orientation) [12]. In advertising research, message framing is usually operationalized by presenting advertising messages in contradictory ways, i.e. by emphasizing the potential positive benefits associated with doing something (i.e. positive framing) or the potential negative consequences of not performing the action (i.e. negative framing) [13].

In the online environment, Awad and Krishnan's study found that when faced with personalized (information-framed) online advertisement consumers may face a choice between the perceived benefits and perceived risks of advertisement relevance and information relevance [14]. Bleier and Eisenbeiss found that information-framed ads outperformed non- information-framed ads when the ads were aligned with consumers' online search motivations, but when the ads did not match consumers' search motivations, this led to negative ratings of the ads. In terms of information framing of advertisements for keyword searches, for example, a message may reinforce the potential gain for online users from clicking on an advertisement, whereas if it is not clicked, the relevant message will emphasize the potential loss [15]. Related research has found that, overall, negatively framed messages are more effective than positively framed messages, due to the fact that consumers perceive negative messages as more diagnostic and place more weight on them in their judgement. However, it is necessary to consider the influence of some relevant factors, such as $\mathrm{Yu}$ and Cude, who explored the phenomenon of gender differences in the perception of message framed advertisements and found that women had higher negative attitudes towards message framed advertisements than men, but were more likely to click on such advertisements [16]; Chan noted that subjects with low cognitive demand showed more infomercial effects than those with high cognitive demand. Also, educated consumers were more influenced by positively framed messages and less educated consumers were more influenced by negatively framed messages [17]. These results suggest that the effects of online advertising message framing (positive versus negative statements) may be context-specific and may vary across conditions. This requires that we select and set up reasonable experimental contexts in relevant studies.

\subsection{The Influence of Cognitive Lock-in Adjustment Orientation and Online Advertising Message Frames on Purchase Decision Patterns and Purchase Intention}

In summary, applying positive and negative statements of message framing can better explain the influence of different language strategies on the purchase intention of the target audience in online advertisements. However, related research needs to introduce a psychological variable that can differentiate between consumer groups - cognitive lock-in adjustment orientation (promotion/defence) - in terms of advertising audience, and introduce a dual-system action model of decision-making (intuition-based/rational-based) in terms of information processing of advertising target audiences, in order to open up the "black box" of consumers' purchase decisions when faced with online advertising information frames [18]. In reality, online advertising information frames are classified into positive (acquisition) and negative (loss) frames according to the presentation of the information, while according to the moderated orientation theory, individuals who are cognitively oriented towards promotion are more interested in approaching positive outcomes (acquisition frame) and those who are defensively oriented are more interested in avoiding negative outcomes (loss frame). Further, when the online advertising message framing is aligned with the consumer's cognitive lock-in adjustment orientation, a regulatory matching effect may be created, as the individual consumer feels that their purchase decision is correct, generates higher perceived value, and is more likely to be persuaded by the online advertising message and further reinforces their behavior intentions [19].

At the same time, individuals with different adjustment orientations tend to exhibit different decision-making and reasoning strategies based on intuition and rationality. In general, individuals with a facilitative orientation will rely more on intuition for their decisions, with reasoning strategies characterized by rapid parallel processing that takes up little or no mental resources, an emphasis on the speed and outcome of decisions, and a distinctly emotional character. Thus, when faced with a positive message framework, consumers with an intuitive purchase decision mode process information more smoothly, experience a greater sense of correctness, and are more likely to make a purchase decision; whereas defensively oriented individuals rely more on rational decision-making, whose reasoning strategies are characterized by slower serial processing, use more mental 
resources, focus on the accuracy and process of decision-making, and are characterised by rational trade-offs and calculations. Negative framing is therefore more conducive to a greater sense of correctness for consumers who adopt a rational purchase decision model. In particular, the above characteristics are particularly evident when the online advertising information frame is matched with the consumer's cognitive targeting adjustment effect [20].

In summary, this paper argues that, firstly, there is an interactive moderating effect between the moderating orientation of consumers' cognitive lock-in and the moderating effect of consumers' purchase intentions, and proposes that:

H1a: positive online advertising messages will lead to higher purchase intentions for consumers with cognitive lock-in promotion orientation compared to those with cognitive lock-in defense orientation; H1b: negative online advertising messages will lead to higher purchase intentions for consumers with cognitive lock-in defense orientation compared to those with cognitive lock-in promotion orientation.

Secondly, the moderating effect of consumer cognitive lock-in is an interaction between the online advertising message framework and consumer purchase decision mode. This paper therefore proposes that:
$\mathrm{H} 2 \mathrm{a}$ : positive online advertising messages will make consumers with cognitive lock-in promotion orientation more likely to adopt an intuition-based purchase decision mode compared to consumers with cognitive lock-in defense orientation;

$\mathrm{H} 2 \mathrm{~b}$ : negative online advertising messages will make consumers with cognitive lock-in defense orientation more likely to adopt a rational-based purchase decision mode compared to consumers with cognitive lock-in promotion orientation.

Thirdly, consumer purchase decision mode is a mediating variable between consumers' cognitive lock-in moderating orientation and online advertising message framing in influencing consumers' purchase intention. Therefore, this paper proposes that:

H3a: consumers' intuition-based purchase decision mode significantly influences their purchase intention;

H3b: consumers' rational-based purchase decision mode significantly influences their purchase intention;

H3c: consumers' purchase decision mode plays a mediating role in the process of consumers' cognitive lock-in moderating orientation and online advertising message framing in influencing consumers' purchase intention.

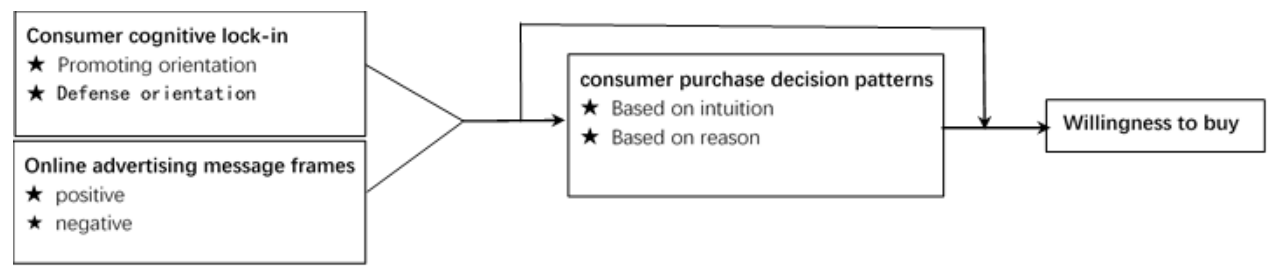

Figure 1: Research model

\section{Study 1: The Effect of Cognitive Lock-in Adjustment Orientation and Online Advertising Message Framing on Consumers' Purchase Intentions}

\subsection{Research Design}

In order to ensure the quality of the experimental study, this study used a live scenario simulation experimental method with the following means to control the experimental process: (1) 65 university students were selected, including 44 undergraduates and 21 postgraduates, and 3 subjects were ineffective in initiating cognitive lock-in adjustment orientations. The valid sample was 62 , of which 26 were male and 36 were female, with a mean age of 20.52 years $(\mathrm{SD}=0.862)$ and a mean monthly consumption expenditure (excluding tuition and fees and accommodation) of RMB 1786 during their school years; (2) all subjects participated in the experiment voluntarily, had never taken part in similar experimental tests and were unaware of the purpose of this experiment; (3) the experimental materials were distributed in a randomized manner;(4) In order to gain the active cooperation of the subjects, the experiment was conducted between or after classes of current undergraduate and postgraduate students of Nanjing University of Finance and
Economics taught by the researcher, with 5-10 usual points as an incentive and each subject was given a small gift in return at the end of the experiment.

Study 1 used a scenario-based experimental test to examine the effects of cognitive lock-in adjustment orientation and online advertising message frames on consumers' purchase intentions. We asked the subjects to simulate an imaginary scenario of browsing a shopping webpage, which was designed with two different frames of promotional advertising messages, i.e. positive/negative (see Table 1), and the subjects were randomly divided into two groups such that each group could only see one type of advertising message, i.e. a positive advertising message group and a negative advertising message group were generated. The corresponding questionnaire was completed after each group of subjects had read the experimental scenario material. In particular, the Adjustment Orientation Questionnaire (Chinese version), revised by Yao Qi, Le Guoan, Wu Chengcong, Li Yanfei and Chen Chen (2008) [21], was used in an online shopping scenario to develop (revise) a questionnaire to measure consumer cognitive lock-in adjustment orientation, allowing subjects to choose between 10 items to manipulate consumer cognitive lock-in adjustment orientation; there were two measures of purchase intention (I will buy this product, I have the intention to buy this product) (Cronbach $\alpha=0.759$ ). A 2 
(cognitive lock-in moderation orientation: facilitative/defensive orientation) $\times 2$ (online advertising message frame: positive/negative) between subjects experimental design was used.

Table 1: Types of online promotional advertising message frames

\begin{tabular}{|c|c|}
\hline rtising & $\begin{array}{l}\text { ertising } \\
\text { e) }\end{array}$ \\
\hline $\begin{array}{l}\text { service recruitment examination } \\
\text { are about to attend an interview } \\
\text { months, when you see a well-knd } \\
\text { training institution released } \\
\text { provincial civil service interv } \\
\text { online school course promo } \\
\text { information: students who attend } \\
\text { online school course train } \\
\text { interview pass rate will be increa } \\
\text { by } 50 \% \text {, and before January } 3 \\
\text { complete the registration, you } \\
\text { get an additional discount of } 2 \\
\text { yuan. }\end{array}$ & $\begin{array}{l}\text { Suppose you have currently passed } \\
\text { the written test for a provincial civil } \\
\text { service recruitment examination and } \\
\text { are about to attend an interview in } 3 \\
\text { months' time, when you see a } \\
\text { well-known training institution } \\
\text { publish a promotional message for a } \\
\text { provincial civil service interview } \\
\text { online course: if you do not attend } \\
\text { the training of this online course, you } \\
\text { will lose the opportunity to increase } \\
\text { your interview pass rate by } 50 \% \text {, and } \\
\text { if you fail to complete the } \\
\text { registration before } 31 \text { January, you } \\
\text { will not be able to get the extra } \\
\text { discount of RMB } 2,000 \text {. }\end{array}$ \\
\hline
\end{tabular}

\subsection{Test of the Effect of Manipulation of Relevant Variables}

The first was a test of the effects of the cognitive lock-in adjustment orientation manipulation. Five statements were used to measure the facilitative orientation of cognitive lock-in, i.e. I am always motivated to work hard to achieve my ambitions and goals; I value good outcomes in the shopping process; I often imagine that I will encounter the good things I want to happen in the shopping process; I prefer to be successful in the process of doing things; and I am more concerned with achieving positive outcomes in my daily life. The same five statements were used to measure the defensive orienting trait of cognitive lock-in, i.e. I often worry about not achieving my ambitions and goals; I value the ability to avoid bad outcomes in the shopping process; I often imagine that I might encounter bad things in the shopping process; I prefer to avoid failure in the process of doing things; and I am more concerned with avoiding mistakes in my daily life. Measured using the Likert 7-point scale, the tested Cronbach alpha values for the two moderated orientations reached 0.687 and 0.673 , respectively. To obtain the dominant moderated orientation category for consumer cognitive lock-in, the mean scores of subjects on the facilitated orientation dimension were generally subtracted from the mean scores on the defensive orientation dimension and dichotomized at the median [22], resulting in the facilitated orientation group and defensive orientation group were 37 and 25 subjects, respectively. Also, to further test the validity of the manipulation of the variable of cognitive lock-in regulation orientation, we used the manipulation questionnaire used in the related study by Pham and Avnet, i.e., after the subjects recalled their ideals and aspirations/responsibilities and duties, they were immediately tested on three decisions, each containing two opposing options (e.g., I would prefer to do what is accepted as the right thing vs. I prefer to do what I want to do, etc.). Again, measured using the Likert 7-point scale, in each decision the larger value corresponded to a facilitative orientation and the smaller value to a defensive orientation (calculated as shown in Table 2) [23].
The results of the independent samples t-test in Table 2 indicate that the mean of the subjects' scores on the three decision items in the conditioning manipulation condition focusing on ideals and achievement was significantly higher than the mean of the scores in the conditioning manipulation condition focusing on responsibility and obligation (M-facilitative orientation $=5.308, \mathrm{M}$-defensive orientation $=4.116, \mathrm{t}(60)=5.307, \mathrm{p}<0.001)$. Therefore, the results of Experiment 1 for the manipulation of cognitive locking conditioning orientations were as expected and successfully met the experimental control.

Table 2: Examination of the effects of the cognitive lock-in orientation manipulation

\begin{tabular}{ccccc}
\hline $\begin{array}{c}\text { Cognitive lock-in } \\
\text { adjustment orientation }\end{array}$ & $\mathrm{M}$ & $\mathrm{SD}$ & $\mathrm{t}$ & $\mathrm{p}$ \\
\hline Promoting orientation & 5.308 & 0.722 & 5.307 & 0.000 \\
Defensive orientation & 4.116 & 0.981 & & \\
\hline
\end{tabular}

The Likert 7 scale ( 1 being strongly disagree and 7 being strongly agree) was then randomly assigned to subjects in the positive and negative advertising message groups to test the manipulation of the online promotional advertising message frame. The test results showed that the mean of the "perceived gain" scores of the subjects in the positive advertising message group was significantly higher than the mean of the "perceived risk avoidance" scores of the subjects in the negative advertising message group (M-benefit acquisition =4.737, M-loss avoidance $=3.340, \mathrm{t}(60)=4.113, \mathrm{p}<0.05)$. Therefore, the experiment successfully manipulated the type of online promotional advertising message frame.

\subsection{Study Results and Discussion}

A $2 \times 2$ ANOVA was conducted using SPSS software to examine the effect of subjects' cognitive locking moderation orientation traits and the type of online promotional advertising message frame on the dependent variable of subjects' willingness to purchase. The valid data after excluding invalid data were analyzed and collated, and the statistical results are shown in Table 3.

Table 3: Statistical results of the interaction between cognitive lock-in adjustment orientation and advertisement message frame type

\begin{tabular}{ccccc}
\hline & \multicolumn{2}{c}{$\begin{array}{c}\text { Positive advertising } \\
\text { messages }\end{array}$} & \multicolumn{2}{c}{$\begin{array}{c}\text { Negative advertising } \\
\text { messages }\end{array}$} \\
\cline { 2 - 5 } & $\mathrm{M}$ & $\mathrm{SD}$ & $\mathrm{M}$ & $\mathrm{SD}$ \\
\hline $\begin{array}{c}\text { Cognitive lock-in } \\
\text { facilitates orientation } \\
\begin{array}{c}\text { Cognitive lock-in } \\
\text { defends orientation }\end{array}\end{array}$ & 5.022 & 1.751 & 4.630 & 1.410 \\
\hline
\end{tabular}

The results of a completely randomized ANOVA on the data in Table 3, using cognitive targeting and advertising message frame type as independent variables and subjects' purchase intention scores as dependent variables (Table 4), show that the main effect of cognitive targeting on moderated targeting was not significant, F-purchase intention $(2,60)=3.579$, $p>0.05$. The main effect of the type of advertising message frame on subjects' purchase intention was also not significant, F- purchase intention $(2,60)=4.131, \mathrm{p}>0.05$; while the main effect of the interaction between moderated targeting and the type of advertising message frame was significantly more significant, F-purchase intention $(2,60)=9.527, \mathrm{p}<0.01$. 
Table 4: ANOVA on the effect of cognitive lock-in adjustment orientation and ad message frame type on purchase intention

\begin{tabular}{clccccc}
\hline Source of variation & Dependent variable & Sum of squares & Freedom & Mean Square & F & Sig. \\
\hline Cognitive lock-in adjustment orientation & Willingness to buy & 6.376 & 2 & 6.376 & 3.579 & 0.083 \\
\hline Ad message frame type & Willingness to buy & 7.716 & 2 & 7.716 & 4.131 \\
\hline $\begin{array}{c}\text { Cognitive lock-in adjustment orientation } \times \\
\text { Ad message frame type }\end{array}$ & Willingness to buy & 15.670 & 2 & 15.670 & 0.057 \\
\hline Error & Willingness to buy & 50.135 & 60 & 2.510 & & 0.003 \\
\hline
\end{tabular}

Note: $* * *$ indicates $\mathrm{P}<0.001, * *$ indicates $\mathrm{P}<0.01$, * indicates $\mathrm{P}<0.05$ (two-tailed)

In summary, there is a matching effect between the cognitive lock-in adjustment orientation and the type of advertising message frame in the purchase decision process, i.e., consumers with promotion orientation have a higher value of "perceived benefit" for positive advertising messages and consumers with defense orientation have a higher value of "perceived risk avoidance" for negative advertising messages. When consumers in both moderating orientations use their preferred type of advertising message frame to make a decision on their purchase intentions, a moderating match is reached, and this matching effect leads to a more positive evaluation of the post-decision choice compared to a moderating mismatch, so that hypotheses $\mathrm{H} 1 \mathrm{a}$ and $\mathrm{H} 1 \mathrm{~b}$ are supported.

\section{Study 2: Influence Mechanisms based on Consumer Purchase Decision Patterns}

\subsection{Activation and Testing of the Effect of Consumer Purchase Decision Mode (Intuition-Based/Rationality- Based)}

Study 2 builds on Study 1 to further examine the matching effect between consumer cognitive targeting and consumer purchase decision mode (intuition-based/ rationality-based), and the mediating role of consumer purchase decision mode in the relationship between cognitive targeting and advertising message frame type on consumer purchase intention. To this end, we initiated and tested the online advertising information framing effect and consumer cognitive lock-in moderated orientation in Study 1. Drawing on the consumer purchase decision mode measurement scale constructed by Samson and Benjamin [24], we used a Likert 7-point scale (1 for strongly disagree and 7 for strongly agree) and randomly assigned subjects to the cognitive lock-in facilitated orientation group and the cognitive lock-in Subjects in the defensive orientation group were measured, and the two purchase decision pattern measures were tested with Cronbach alpha values of 0.715 and 0.702 , respectively. A further test of the manipulation of consumer purchase decision patterns showed that the mean of the "intuition-based" scores of the subjects in the cognitive lock-in facilitated orientation group were significantly higher than the "rationality-based" scores of the subjects in the cognitive lock-in defensive orientation group (M-based on intuition $=4.851$, M-based on reason $=3.227, \mathrm{t}(60)=9.441$, $\mathrm{p}<0.01)$. Therefore, the experiment successfully manipulated the type of consumer purchase decision pattern.

\subsection{The Effect of Cognitive Lock-in Adjustment Orientation and the Type of Advertising Message Frame on Consumer Purchase Decision Patterns}

The results of a completely randomized ANOVA on the data in Table 3, using cognitive targeting as the independent variable and advertising message frame type as the dependent variable, show that (Table 5): the main effect of cognitive targeting as the moderator was not significant, F- purchase decision mode $(2,60)=3.662, p>0.05$; the main effect of advertising message frame type on subjects' purchase intention was also not significant, F-purchase decision mode $(2,60)=4.005, p>0.05$. The main effect of the type of advertising message frame on subjects' purchase intention was also not significant, F-purchase decision mode (2, $60)=4.005, \mathrm{p}>0.05$; while the main effect of the interaction between moderated targeting and the type of advertising message frame was significantly more significant, F-purchase decision mode $(2,60)=11.221, \mathrm{p}<0.01$.

Table 5: ANOVA on the effect of cognitive lock-in adjustment orientation and ad message frame type on purchase decision

\begin{tabular}{|c|c|c|c|c|c|c|}
\hline \multicolumn{7}{|c|}{ model } \\
\hline Source of variation & Dependent variable & Sum of squares & Freedom & Mean Square & $\mathrm{F}$ & Sig. \\
\hline Cognitive lock-in adjustment orientation & purchase decision model & 5.771 & 2 & 5.771 & 3.662 & 0.091 \\
\hline Ad message frame type & purchase decision model & 7.062 & 2 & 7.062 & 4.005 & 0.062 \\
\hline $\begin{array}{c}\text { Cognitive lock-in adjustment orientation } \times \\
\text { Ad message frame type }\end{array}$ & purchase decision model & 17.335 & 2 & 17.335 & $11.221^{* *}$ & 0.003 \\
\hline Error & purchase decision model & 55.319 & 60 & 3.812 & & \\
\hline
\end{tabular}

Note: $* * *$ indicates $\mathrm{P}<0.001, * *$ indicates $\mathrm{P}<0.01$, * indicates $\mathrm{P}<0.05$ (two-tailed)

In summary, there is also a matching effect between cognitive lock-in regulation orientation and the type of advertising message frame in the choice of purchase decision mode (intuition-based/rational-based), i.e. positive online advertising messages will make consumers with cognitive lock-in promotion orientation more likely to adopt an intuition-based purchase decision mode compared to consumers with cognitive lock-in defence orientation, while negative online advertising messages will make consumers with cognitive lock-in promotion orientation more likely to adopt a rational-based purchase decision mode compared to consumers with cognitive lock-in promotion orientation (see Figure 2). Negative online advertising messages will make cognitively locked defensively oriented consumers more inclined to adopt a rational purchase decision mode (see Figure 3). Thus, hypotheses $\mathrm{H} 2 \mathrm{a}$ and $\mathrm{H} 2 \mathrm{~b}$ are supported. 


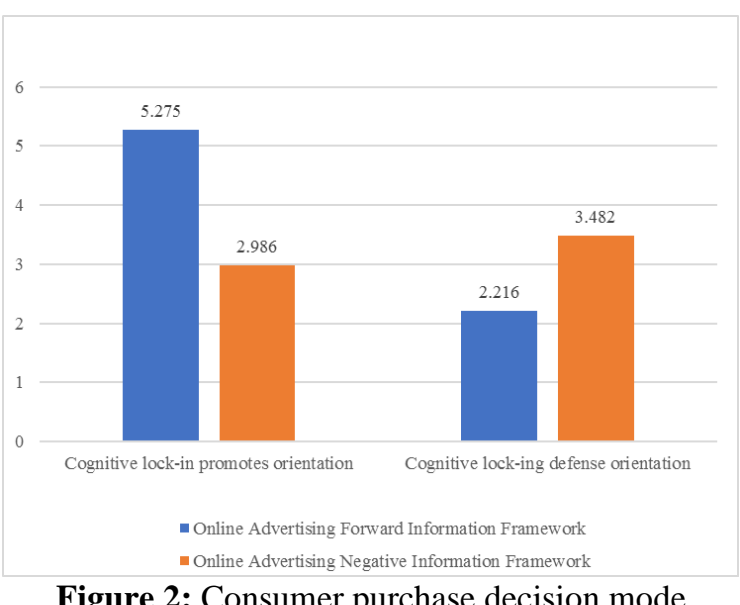

Figure 2: Consumer purchase decision mode (intuition-based)

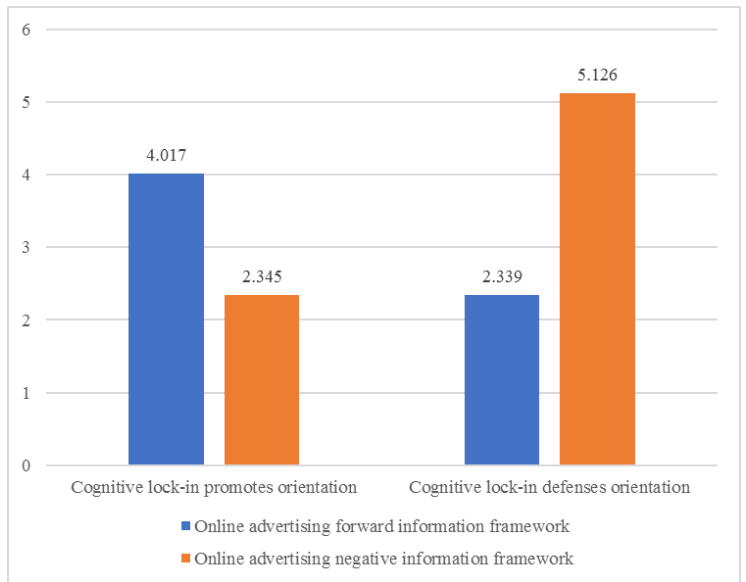

Figure 3: Consumer purchase decision mode (rationality-based)

\subsection{Analysis of the Mediating Role of Consumer Purchase Decision Patterns (Intuition-Based/Rational-Based)}

The mediating role of the consumer purchase decision model (intuition-based/rational-based) was tested using regression analysis, the results of which are shown in Table 6. Models 1 to 4 tested the mediating role of the intuition-based purchase decision model. At the same time, the mediating variable has a partial mediating role in the effect of the independent variable on the dependent variable. Based on the same approach, Model 1 and Models 5 to 7 in Table 6 test the mediating role of the rationality-based purchase decision model, and the results show that the consumer purchase decision model (intuition-based/rationality-based) partially mediates the effect of cognitive locking adjustment orientation and the type of advertising message frame on consumer purchase intention, thus hypothesis $3 \mathrm{c}$ is tested. Models 3 and 6 , on the other hand, showed that both intuition-based $\left(0.416^{* * *}\right)$ and rationality-based $(0.242 * *)$ purchase decision models significantly influenced consumers' purchase intention, thus hypothesis $3 \mathrm{a}$ and $3 \mathrm{~b}$ were tested.

Study 2 introduces a set of mediating variables, consumer purchase decision mode (intuition-based/rational-based), to examine the mechanisms by which cognitive lock-in moderates targeting and the type of advertising message frame on consumer purchase intentions. The results of the experimental study show that the mediating role of consumer purchase decision mode (intuition-based/rational-based) is more significant: consumers with an intuitive purchase decision mode show higher purchase intentions than those with a rational purchase decision mode under facilitated targeting and positive online advertising messages, while consumers with a rational purchase decision mode show higher purchase intentions under preventive targeting and negative online advertising messages. In the case of precautionary targeting and negative online advertising messages, consumers using the rational purchase decision model showed higher purchase intentions than those using the intuitive purchase decision model.

Table 6: Results of the analysis of the mediating role of consumer purchase decision patterns (intuition-based/rational-based)

\begin{tabular}{|c|c|c|c|c|c|c|c|}
\hline & Model 1 & Model 2 & Model 3 & Model 4 & Model 5 & Model 6 & Model 7 \\
\hline Variate & $\begin{array}{l}\text { Willingness } \\
\text { to buy }\end{array}$ & $\begin{array}{l}\text { Based on } \\
\text { intuition }\end{array}$ & $\begin{array}{l}\text { Willingness } \\
\text { to buy }\end{array}$ & $\begin{array}{l}\text { Willingness } \\
\text { to buy }\end{array}$ & $\begin{array}{l}\text { Based on } \\
\text { rationality }\end{array}$ & $\begin{array}{l}\text { Willingness } \\
\text { to buy }\end{array}$ & $\begin{array}{l}\text { Willingness } \\
\text { to buy }\end{array}$ \\
\hline $\begin{array}{l}\text { Cognitive lock-in adjustment orientation } \times \\
\text { Online advertising information frames }\end{array}$ & $\begin{array}{l}0.522 * * * \\
(4.764)\end{array}$ & & & & & & \\
\hline $\begin{array}{l}\text { Cognitive lock-in adjustment orientation } \times \\
\text { Online advertising information frames }\end{array}$ & & $\begin{array}{c}0.473 * * * \\
(3.851)\end{array}$ & & & & & \\
\hline Intuition-based purchase decision model & & & $\begin{array}{c}0.416 * * * \\
(3.620)\end{array}$ & & & & \\
\hline $\begin{array}{l}\text { Cognitive lock-in adjustment orientation } \times \\
\text { Online advertising information frames }\end{array}$ & & & & $\begin{array}{l}0.546 * * * \\
(5.332)\end{array}$ & & & \\
\hline Intuition-based purchase decision model & & & & $\begin{array}{l}0.235^{* * *} \\
(2.562)\end{array}$ & & & \\
\hline $\begin{array}{l}\text { Cognitive lock-in adjustment orientation } \times \\
\text { Online advertising information frames }\end{array}$ & & & & & $\begin{array}{c}0.484 * * * \\
(4.707)\end{array}$ & & \\
\hline Rational-based purchase decision model & & & & & & $\begin{array}{c}0.242 * * \\
(3.078)\end{array}$ & \\
\hline $\begin{array}{l}\text { Cognitive lock-in adjustment orientation } \times \\
\text { Online advertising information frames }\end{array}$ & & & & & & & $\begin{array}{c}0.537 * * * \\
(4.972)\end{array}$ \\
\hline Rational-based purchase decision model & & & & & & & $\begin{array}{c}0.271 * * * \\
(3.886)\end{array}$ \\
\hline R2 & 0.181 & 0.162 & 0.156 & 0.210 & 0.175 & 0.127 & 0.203 \\
\hline F & $11.672 * * *$ & $5.611^{* * *}$ & $9.755 * * *$ & $14.116^{* * *}$ & $4.756^{* *}$ & $11.411 * * *$ & $12.512 * * *$ \\
\hline
\end{tabular}

Note: $* * *$ indicates $\mathrm{p}<0.001 ; * *$ indicates $\mathrm{p}<0.01, \mathrm{t}$ in parentheses. 


\section{Conclusions and Implications}

The message frames used in this study are actually operationalized presentations of online advertising messages that emphasize the potential positive benefits associated with doing something (i.e. positive frames) or the potential negative consequences of not performing an action (i.e. negative frames). At the same time, the results of the experimental study show that there is a significant interaction between consumers' cognitive lock-in regulatory orientation and online advertising information framework. Once the regulatory orientation matches the types of online advertising information framework, coupled with the mediating role of consumers' purchase decision-making model (based on intuition / based on rationality), consumers' higher purchase intention will be stimulated. As the main concern of advertisers (merchants) is what message is most effective under what conditions and to whom, the findings of this paper may provide some assistance to merchants in improving the effectiveness of online advertising.

\section{(1) To have a deeper insight into consumers}

First of all, we must pay attention to the characteristics of consumers' cognitive lock-in adjustment orientation. Many studies, including this research, have confirmed that the cognitive lock-in adjustment orientation, as an individual's stable personality trait, has a profound impact on the purchase decision mode and purchase intention of consumers, but it has not attracted enough attention from merchants. Therefore, merchants should pay attention to tracking, summarizing and categorizing consumers' online shopping browsing and transaction behavior records, and based on this, the cognitive locking adjustment characteristics of consumers are analyzed and classified to provide basic data for improving the pertinence of promotional information and marketing accuracy. Secondly, we should pay attention to the consumption goals that consumers intend to achieve. Driven by consumers' cognitive lock-in adjustment orientation characteristics, consumers' consumption goals can be roughly divided into two categories: profit-seeking and risk-averse, and their purchase willingness is determined by the combined effect of internal psychological factors and external promotional stimuli. Therefore, when an enterprise develops an online promotion plan, it must specify the target setting and have a strong correlation with other cognitive frameworks of the target, such as the attainability of the target. At the same time, businesses should communicate as few vague, abstract goals as possible that are not easy to achieve or measure; third, they must understand how consumers perceive and remember online advertisements. In view of the abundance of information on the Internet, a large number of advertisements in different formats on a single webpage will cause confusion in advertising information, which will increase consumers' advertising evasion and reduce consumers' memory of online advertisements. So, when designing and publishing online advertisements, businesses must consider both the information characteristics of the advertisements and the media preferences of online users in order to match consumers' perception and memory of advertisements.

(2) To set up a richer online shopping experience scenario
Customer experience is considered to be a purely subjective and comprehensive interaction process based on cognitive and emotional cues, adjusted by customers and their related psychological characteristics, and finally forming unique consumer memories or feelings (such as pleasant/unpleasant, intuitive/rational, etc.) The results of this experiment show that consumers' purchase decision patterns play a significant mediating role in the process of cognitive lock-in adjustment orientation and advertising information frame type affecting consumers' purchase intention, and both intuitive and rational purchase decision patterns are based on certain shopping experience. Therefore, it is necessary for businesses to re-evaluate persuasive advertising models. For example, when businesses face consumers who promote adjustments, they can use promotional (positive) content to design product descriptions while using discounts to present promotional money information, that is, the description of the attributes and characteristics of promotional products, should be presented in more positive terms, so as to enhance consumers' benefited experience of related promotional products. Furthermore, merchants can consider designing multiple shopping decision-making scenes in the same product promotion activity, so that the original dull interaction method becomes vivid and lively, which not only brings a brand new experience to consumers, but also has a strong exposure effect on the visual memory of consumers, and is more likely to trigger behavioral effects in the future.

(3) To improve the pertinence of advertising content and achieve accurate push

In essence, the match between the information frame effect and the adjustment orientation is the match between the product itself and the consumer. Merchants should pay attention to the presentation of product information that can communicate with consumers, and improve the pertinence of advertising content.

To this end, businesses should subdivide and manage target customers according to their personality traits and information processing motivation characteristics, and create and design corresponding advertising content according to customers' different cognition and needs. For example, when the target customers' cognition has a big difference with the characteristics of information processing motivation, the difference in the advertising content itself can be used to initiate the corresponding cognitive lock-in adjustment orientation of the target customers, and based on this, the matching advertising information frame can be designed to improve the persuasiveness of the advertising, thereby improving the controllability of advertising design to realize precise push.

Conditional e-commerce platforms can use machine learning to automatically capture and match consumers' adjustment orientation characteristics with the information frame type of online promotional advertisements, thereby increasing consumers' perceived value and purchase willingness about promotional programs, and achieving precision marketing with higher efficiency.

\section{Acknowledgement}


This work is supported by the Fund Project: Scientific Research Project of Jiangsu Society Higher Education "14th five year plan": "Research and Practice on the reform of "dual core drive' training mode of high-quality marketing professional talent training under the background of new liberal arts" (YB105); Teaching Reform Project of Chinese Society for Higher Education "Research on digital teaching resource design and quality evaluation of marketing courses in colleges and universities" (2020SZYB07); and "Marketing" School-level Brand Major Construction Project of Nanjing University of Finance \& Economics (2020).

\section{References}

[1] Jiang Yushi. An Empirical Study on the Impact of Online Behavioral Targeted Advertising on Consumer Attitudes [J]. Social Scientist, 2017 (1): 58-66.

[2] MURRAY K B, HÄUBL G. Explaining cognitive lock-in: the role of skill-based habits of use in consumer choice [J]. Journal of Consumer Research, 2007, 34(1): 77-88.

[3] HUNG-PIN SHIH. Cognitive lock-in effects on consumer purchase intentions in the context of B2C web sites [J]. Psychology and Marketing, 2012, 29(10): 738-751.

[4] LIN L, HU P J, SHENG O R, et al. Is stickiness profitable for electronic retailers? [J]. Communications of the ACM, 2010, 53(3): 132-136.

[5] HIGGINS E T. Beyond pleasure and pain [J]. American Psychologist, 1997, 52(12): 1280-1300.

[6] HIGGINS E T Making a good decision: Value from fit [J]. American Psychologist, 2000, 55(11): 1217-1230.

[7] STANOVICH K E, WEST R F. Individual differences in reasoning: Implications for the rationality debate? [J]. Behavioral and Brain Sciences, 2000, 23(5): 645-726.

[8] JOHNSON E. J, BELLMAN S, LOHSE G. Cognitive lock-in and the power law of practice [J]. Journal of Marketing, 2003, 67(2): 62-75.

[9] OLIVER R L. Whence consumer loyalty? [J]. Journal of Marketing, 1999, 63(4): 33-44.

[10] Fang Shirong. Long-term orientation of marketing channel members and partnerships and inter-organizational performance $[\mathrm{J}]$. Management Review, 2003, 2(2): 5-8.

[11] SYLVAIN S, MARC F, PIERRE-MAJORIQUE L, et al. Consumers' cognitive lock-in on websites [J]. Journal of Internet Commerce, 2015, 14 (3):277-293.

[12] KAHNEMAN D, TVERSKY A. Prospect theory: an analysis of decision under risk [J]. Econometrica, 1979, 47(2): 263-291.

[13] SHIV B, EDELL BRITTON J A, PAYNE J W. Does elaboration increase or decrease the effectiveness of negatively versus positively framed messages? [J]. Journal of Consumer Research, 2004, 31(1): 199-208.

[14] AWAD N F, KRISHNAN M S. The personalization privacy paradox: An empirical evaluation of information transparency and the willingness to be profiled online for personalization [J]. MIS Quarterly, 2006, 30 (1): 13-28.

[15] BLEIER A, EISENBEISS M. Personalized online advertising effectiveness: The interplay of what, when, and where [J]. Marketing Science, 2015, 34(5): 669-688.

[16] YU J H, CUDE B. "Hello, Mrs. Sarah Jones! We recommend this product!" Consumers' perceptions about personalized advertising: Comparisons across advertisements delivered via three different types of media [J]. International Journal of Consumer Studies, 2009, 33(4): 503-514.

[17] CHAN Y Y. Interplay of message framing, keyword insertion and levels of product involvement in click-through of keyword search ads [J]. International Journal of Advertising, 2011, 30(3): 399-424.

[18] LI X, LING W. How framing effect impact on decision making on internet shopping $[\mathrm{J}]$. Open Journal of Business and Management 2015, 3(1): 96-108.

[19] PARK S, KIM M Y. The impact of attribute importance in the effects of option framing on choice: budget range and justification as moderators of loss aversion [J]. Psychology \& Marketing, 2012, 29(10): 726-737.

[20] KHAN S K, ALI N, KHAN N A, AMMARA U, ANJUM N. Understanding multiscreening phenomenon for online shopping through perspective of self-regulation and dual process theory: Case of Chinese young generation $[\mathrm{J}]$. Electronic Commerce Research and Applications, 2020, 42(1): 1-14.

[21] Yao Qi, Le Guoan, Wu Chengcong, Li Yanfei, Chen Chen. The measurement dimensions of adjustment orientation and the reliability and validity of the questionnaire [J]. Applied Psychology, 2008 (4): 318-323.

[22] HIGGINS E T. Promotion and prevention experiences: relating emotions to non-emotional motivational states [C]. in J.P. Forgas (eds.), Handbook of affect and social cognition, Hillsdale, NJ, Lawrence Erlbaum Associates, 2001, pp. 186-211.

[23] PHAM M T, AVNET T. Ideals and oughts and the reliance on affect versus substance in persuasion $[\mathrm{J}]$. Journal of Consumer Research, 2004, 30(4): 503-518.

[24] SAMSON A, BENJAMIN G V. Emergency purchasing situations: implications for consumer decision- making [J]. Journal of Economic Psychology, 2014, 44(4): 21-33.

\section{Author Profile}

Xinyang Wu(2000-), female, from Xuzhou, Jiangsu Province, master of marketing and Logistics Management School of Nanjing University of Finance and economics, majoring in consumer behavior.

Baocheng Sun(1996-), male, born in Suihua, Heilongjiang Province, is a master student in the school of marketing and logistics management of Nanjing University of Finance and economics. His research direction is consumer behavior. 